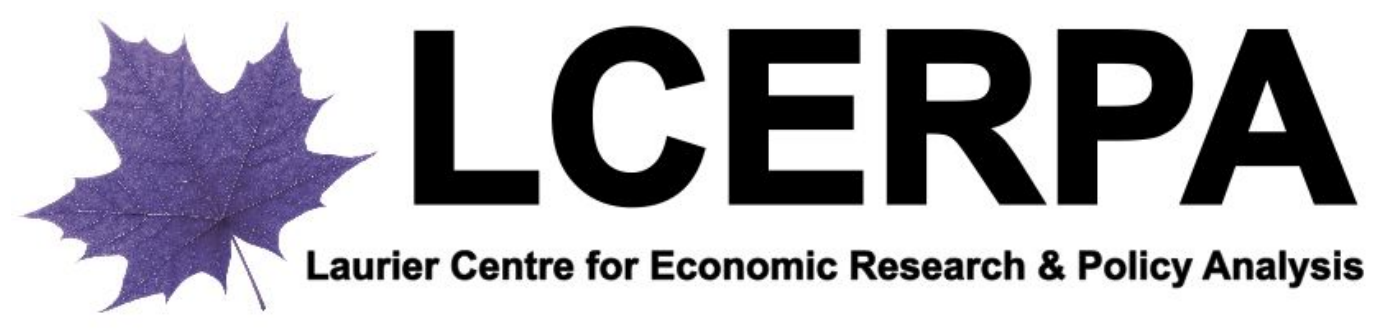

LCERPA Working Paper No. 2017-5

June 2017

\title{
Revisiting the Macroeconomic Effects of Labor Reallocation
}

Emmanouil Gkiourkas, Department of Economics, University of Macedonia Theodore Panagiotidis, Department of Economics, University of Macedonia and Rimini Centre for Economic Analysis

Gianluigi Pelloni, Rimini Centre for Economic Analysis, Department of Economics, Wilfrid Laurier University, and Department of Economics, University of Bologna 


\title{
Revisiting the macroeconomic effects of labor reallocation
}

\author{
Emmanouil Gkiourkas $^{a}$ Theodore Panagiotidis $^{a, b}$ Gianluigi Pelloni $^{b, c, d}$
}

9th June 2017

a Department of Economics, University of Macedonia, Greece, tpanag@uom.gr

b Rimini Centre for Economic Analysis (RCEA), Canada

c Department of Economics, Wilfrid Laurier University, Canada

d Department of Economics, University of Bologna, Italy

We revisit the macroeconomic effects of labor reallocation within the framework of Campbell and Kuttner (1996). We re-estimate their model, update the sample, and employ generalized and local impulse response functions. We confirm that total employment responses to reallocation shocks remain significant.

JEL classification: C32, C50, E24

Keywords: labor reallocation, unemployment, sectoral shifts 


\section{Introduction}

Campbell and Kuttner 1996 (CK hereafter) provide a seminal paradigm for testing and measuring the macroeconomic effects of labor reallocation devoid of dispersion measures à la Lilien (1982) and so bypass difficulties linked to such proxies (see Gallipoli and Pelloni, 2013, for a review of the literature).

This paper extends CK in four directions: first, we extend the sample (60 years overall); second, we consider recent developments in time series econometrics (Jorda 2005 and 2009); third, we take into account the intrinsic asymmetries of sectoral shifts following Kilian and Vigfusson (2011); and fourth, we consider the effects of real exchange rate shocks on reallocations. This analysis focuses on the response of total employment to sectoral shocks (impulse responses within a VAR framework).

The results confirm CK that sectoral shifts play a significant role in the fluctuations of total employment. Moreover, there is evidence that the magnitude of the impact of reallocation shocks has decreased when one considers an up to date sample.

\section{Sectoral Shifts}

We estimate a twelve lags specification of CK's bivariate SVAR. The reduced form of the model for $\rho$ lags can be written as follow:

$$
y_{t}=B y_{t}+A_{1} y_{t-1}+A_{2} y_{t-2}+\ldots .+A_{\rho} y_{t-\rho}+\varepsilon_{t}
$$

where $y_{t}=[D N, D W]$ is the vector of the endogenous variables, $B$ is an identity $2 \mathrm{x} 2$ matrix for the contemporaneous effects, $A_{\rho}$ is a $2 x 2$ coefficient matrix for the lagged values and $\varepsilon_{t}=\left[u_{t}, v_{t}\right]$ is the vector that contains the uncorrelated aggregate and sectoral shocks respectively. The endogenous variables are log-differences of total employment, DN, and manufacturing's share, DW (following CK's notation). We employ short-run and long-run restrictions (see the appendix).

Real exchange rate changes could affect unemployment via both an aggregate and a reallocation channel. However, Gourinchas (1998), Davis and Haltiwanger (2001), Klein et al. (2003) and Haltiwanger et al. (2004) bear out that both job creation and destruction would move in the same direction in response to a real exchange rate disturbance. Such a response should support the view of a pure reallocation shock, since an aggregate shock should have brought about diverging responses of job creation and destruction. Thus we add a third equation for the real effective exchange rate (E) to the baseline bivariate VAR and impose the same restrictions as in the case of $D Z$.

We also re-estimate CK's seven-dimensional VAR (employment shares of six sectors and aggregate employment) to capture much of the inter-sectoral reallocation missed by the bivariate structure. We adopt the same sectoral disaggregation of CK 
(construction; fire, insurance and real estate (FIRE); transportation; wholesale and retail trade; and Government) and do not orthogonalize sectoral shocks (no natural ordering of these variables).

We employ the generalised impulse responses (GIRFs) of Pesaran and Smith (1998) and the local impulse responses (local IRF) of Jorda (2005, 2009).

Finally, given the intrinsic asymmetries of sectoral shifts (Panagiotidis and Pelloni, 2014), we test the asymmetric responses of total employment to changes in manufacturing share. Following Kilian and Vigfusson (2011), we compute a Wald-type test ${ }^{1}$ to examine the case of asymmetry. The VAR employed contains the vector of endogenous variables $y_{t}=\left[D N, D W^{+}, D W^{-}\right]$, where + and - indicate that manufacturing share is censored to contain only positives or only negative values ${ }^{2}$.

\section{Empirical Results}

Table 1 presents the data. The sample ranges from 1955M02 to 2016M08. Table 2 summarises the specifications and reports the variance decomposition analysis of all the models together with the initial CK estimates. The focus is on the share of sectoral shocks to the variance of total employment. It is evident that the identification assumptions have an effect on the results. When sectoral shifts are restricted not to have a contemporaneous impact on aggregate variables, they account for a relatively smaller portion of the variance. When total employment does not affect the other sector in the long-run, the variance share of the sectoral shocks ranges from $48.1 \%$ (2 sectors) to $84.7 \%$ ( 7 sectors). Full sample results suggest that the impact of reallocation shocks tends to fall. When sector disaggregation increases, sectoral shocks account for $1 / 4$ of the variance of total employment even within the unfavorable short-run restricted SVAR.

Figure 1 presents the impulse responses of the two-sectors model, comparing the CK's sample and the updated one. Shocks on the manufacturing sector affect total employment through the alternative functions and identifying assumptions. GIRFs and local IRFs from the simple VAR indicate for the CK's span that a one standard deviation shock to the growth rate of manufacturing's employment share causes an almost $0.1 \%$ increase in the growth rate of total employment. In comparison, sectoral shifts within the full sample affects aggregate employment for about $25 \%$ less. Shocks from the GIRFs are significant for almost six periods, while those from the local IRFs for two periods. Both produce positive responses. For the SVAR, the longrun restricted model behaves in line with the GIRFs and the local IRFs. The latter confirms the robustness of the CK's results to alternative methods of calculating the impulse responses.

\footnotetext{
${ }^{1}$ The $p$-value of the relevant F-statistic is 0.0206 . All results are available upon request.

${ }^{2}$ Note that sectoral shifts are not directional and only the size of the shock would matter. It is worth investigating whether the shock is significant in the case where this directional assymetry is taken into account.
} 
Figure 2 refers to the model that introduces oil shocks that affect manufacturing contemporaneously and aggregate employment indirectly. The magnitude of the sectoral shocks identified with this, decreases by almost $50 \%$ for the GIRFs and $40 \%$ for the local IRFs (full sample). Shocks are statistically significant for six and two periods respectively. Innovations from SVARs have no statistical significanc ${ }^{3}$

In Figure 3, we replace total employment with total unemployment as well as oil price shocks with commodity price and exchange rate disturbances. Structural shocks continue to have no impact. Both commodity price and exchange rate innovations influence unemployment, through the manufacturing sector, in the same manner. The responses are negative and significant for three periods.

Finally, Figure 4 shows the asymmetric impulse response analysis in the sense of Killian and Vigfusson (2011) for the full sample. From both the GIRF and the local IRF the impact of the shock coming from negative growth rates of the manufacturing share seems to be greater than the positive ones, in terms of their mean point estimates

\section{Conclusions}

This paper examines the importance of labor reallocation. Alternative impulse response functions and variance decomposition analysis for VARs and SVARs are estimated to gauge the impact of sectoral shocks. Results from the benchmark model (CK) indicate that sectoral shifts' innovations are reduced by $25 \%$ when incorporating the up-to-date sample. Although the magnitude of this impact has decreased, responses of total employment to reallocation shocks remain statistically significant. The alternative methods for calculating the impulse responses provide similar conclusions, revealing that the CK results are robust. In the case of the 7 sector disaggregation, the variance decomposition analysis shows that, even in the most unfavorable scenario for sectoral shocks specification, these shocks account for almost $20 \%$ of the variance of aggregate employment. Reallocation shocks remain a significant source of aggregate employment's fluctuations.

\footnotetext{
${ }^{3}$ Thus, we cannot refer to manufacturing as a transmission channel.

${ }^{4}$ This difference is close to $15 \%$. Nonetheless, the impact response for the negative sectoral values appears to be within the confidence interval of the positive ones and vice versa.
} 


\section{References}

Abraham, K.G. and Katz L.F., (1986). Cyclical Unemployment: Sectoral Shifts or Aggregate Disturbances. Journal of Political Economy, 94: 507-522.

Campbell, J.R. and Kuttner, K.N., (1996). Macroeconomic effects of employment reallocation. Carnegie-Rochester Conference Series on Public Policy, 44, 87-116.

Davis, S. J., and J. Haltiwanger (2001), Sectoral Job Creation and Destruction Responses to Oil Price Changes, Journal of Monetary Economics, 48(3), 465-512.

Gallipoli, G., Pelloni, G., (2013). Macroeconomic Effects of Job Reallocations: A Survey. Review of Economic Analysis 5, 127-176.

Gourinchas P.-O., (1999), Exchange Rates and Jobs: What Do We Learn from Job Flows? NBER Chapters, in: NBER Macroeconomics Annual 1998, 13, 153-222.

Haltiwanger, J., A. Kugler, M. Kugler, A. Micco and C. Pages (2004), Effects of Tariffs and Real Exchange Rates on Job Reallocation: Evidence from Latin America, Journal of Policy Reform, 7(4), 191-208.

Jordà, O., (2005). Estimation and Inference of Impulse Responses by Local Projections, American Economic Review, 95(1): 161-182.

Jordà, O., (2009). Simultaneous Confidence Regions for Impulse Responses, The Review of Economics and Statistics, 91(3), 629-647.

Kilian, L. and Vigfusson, R.J., (2011). Are the responses of the U.S. economy asymmetric in energy price increases and decreases? Quantitative Economics, 2, 419-453.

Klein, M. W., Scott Schuh, and R. K. Triest. (2003), Job Creation, Job Destruction, and the Real Exchange Rate, Journal of International Economics, 59(2), 239-265.

Lilien, D., (1982). Sectoral Shifts and Cyclical Unemployment. Journal of Political Economy, 90: 777-793.

Loungani, P., (1986). Oil Price Shocks and the Dispersion Hypothesis. Review of Economics and Statistics, 68: 536-539.

Panagiotidis, T. and Pelloni G., (2014). Asymmetry and Lilien's Sectoral Shifts Hypothesis: A Quantile Regression Approach. Review of Economic Analysis, 6: 68-86. 


\section{Tables and Figures}

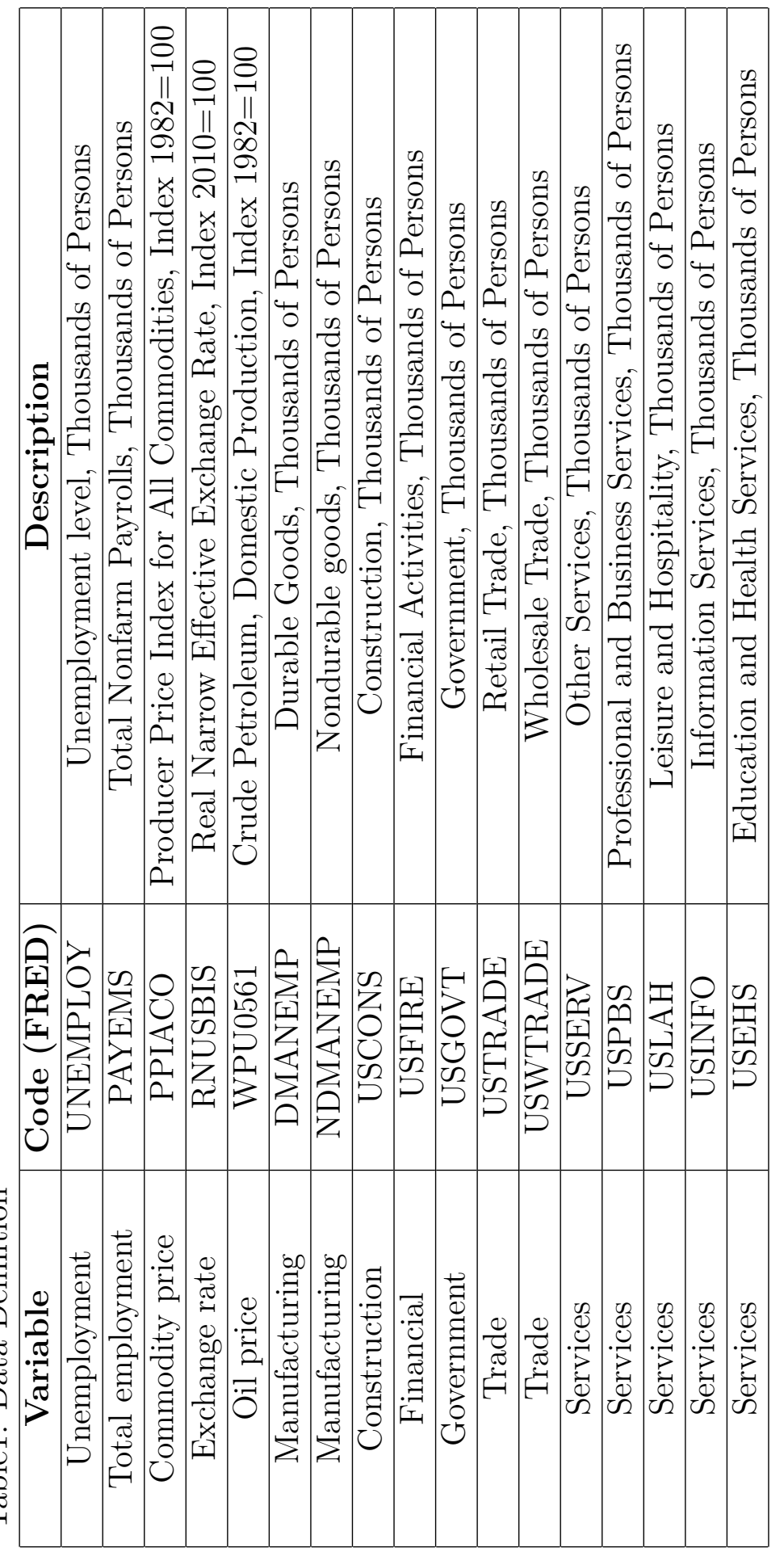




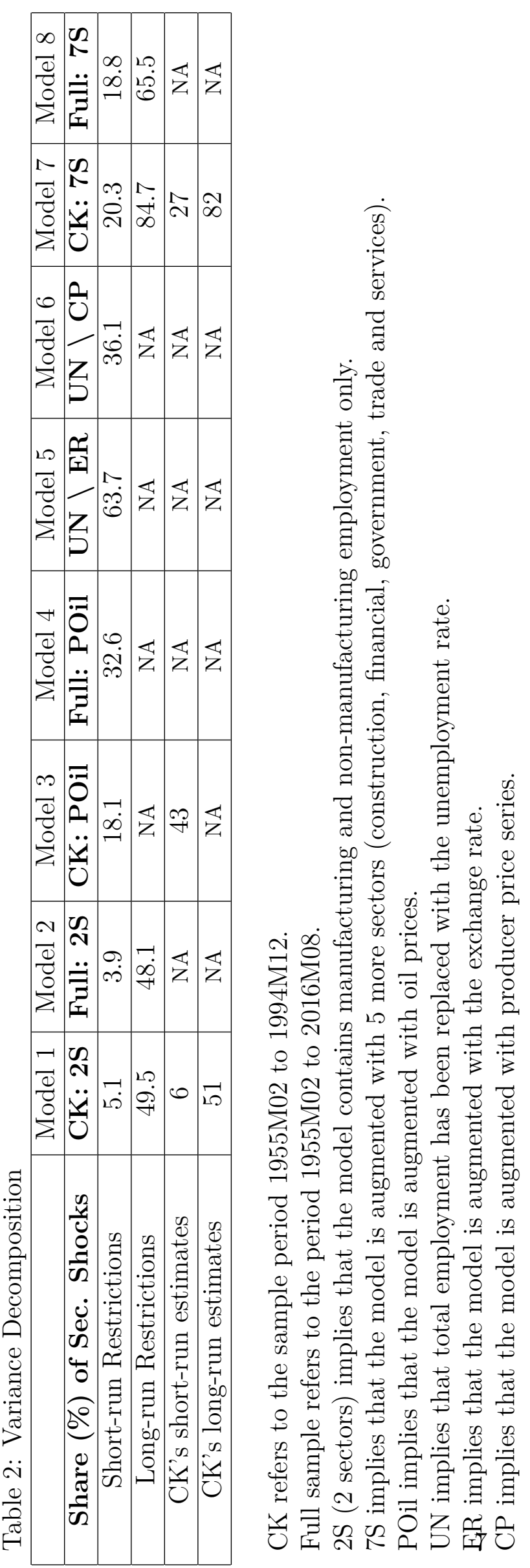


Figure 1: The response of total employment to reallocation shocks, two-sector specification

GIRF, 1955M02-1994M12

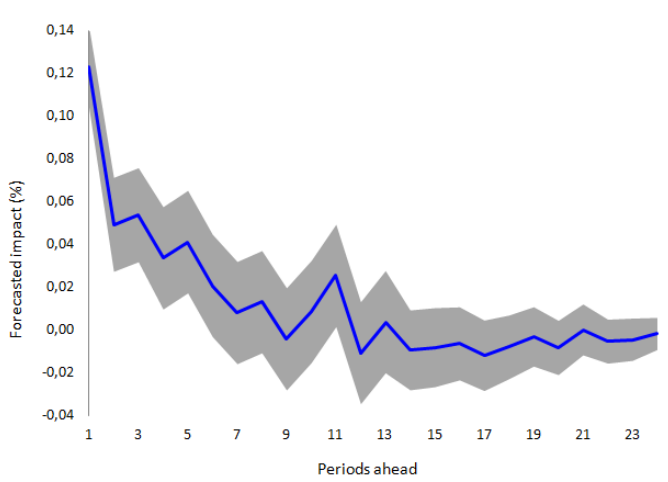

Local IRF, 1955M02-1994M12

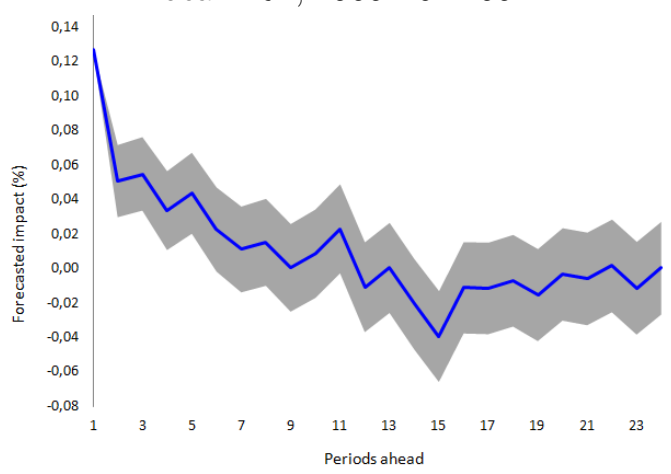

Short-run SVAR IRF, 1955M02-1994M12

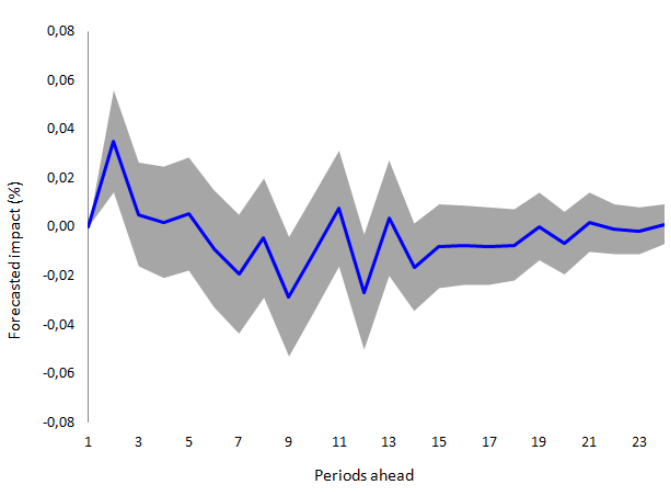

Long-run SVAR IRF, 1955M02-1994M12

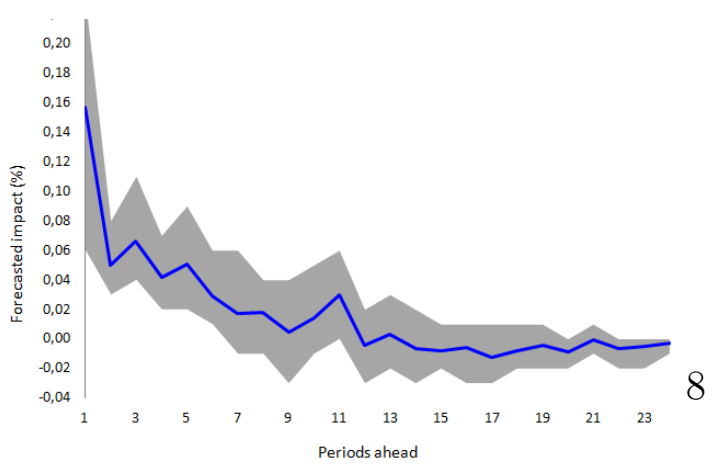

GIRF, 1955M02-2016M08

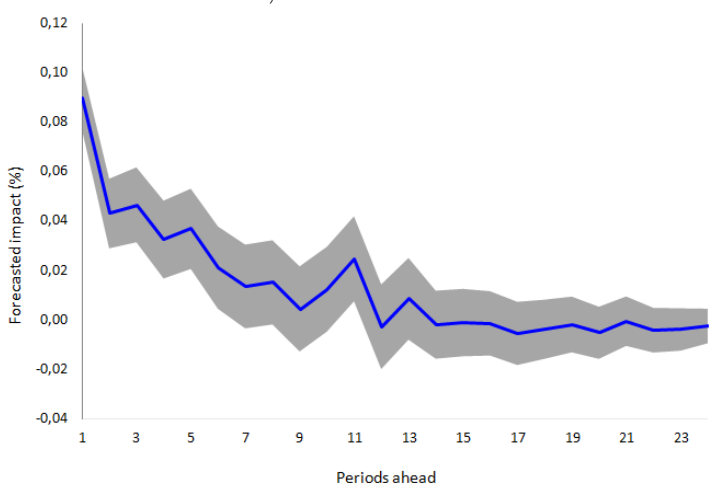

Local IRF, 1955M02-2016M08

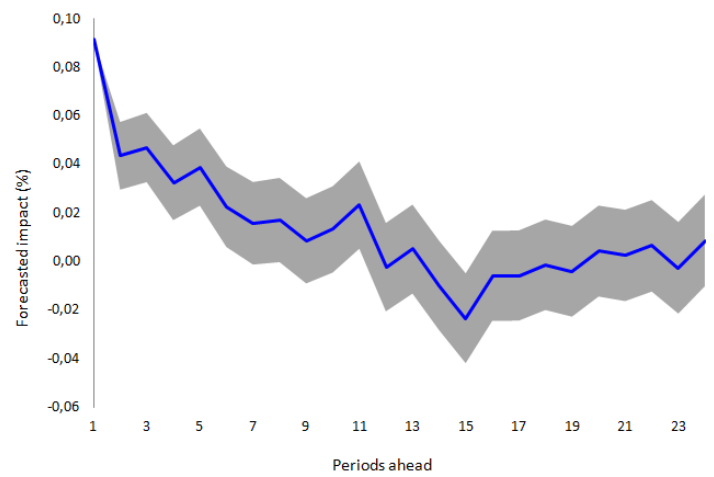

Short-run SVAR IRF, 1955M02-2016M08

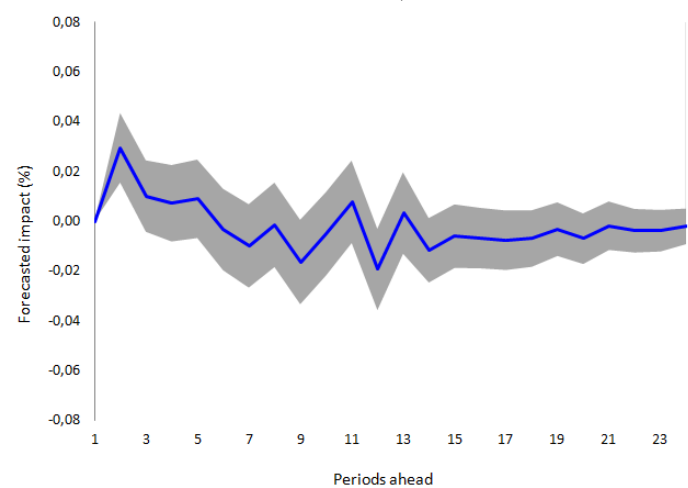

Long-run SVAR IRF, 1955M02-2016M08

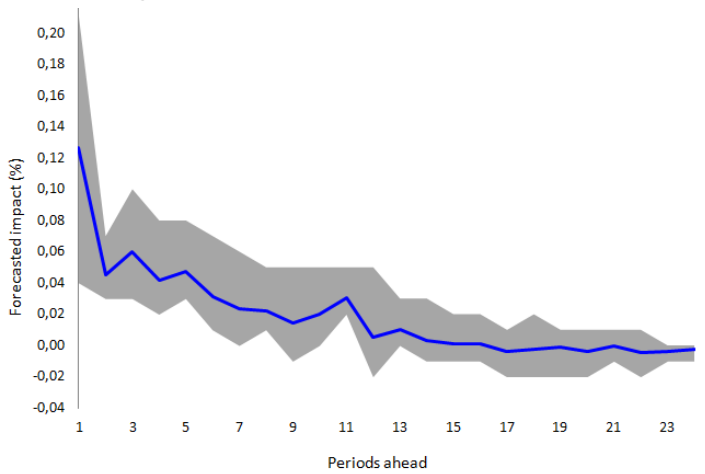

*The shaded areas for the GIRFs and the structural IRFs represent the \pm 2 asymptotic S.E. confidence bands, while those for the local IRFs represent the $95 \%$ marginal ones. 
Figure 2: The response of total employment to reallocation shocks, oil prices augmented VAR
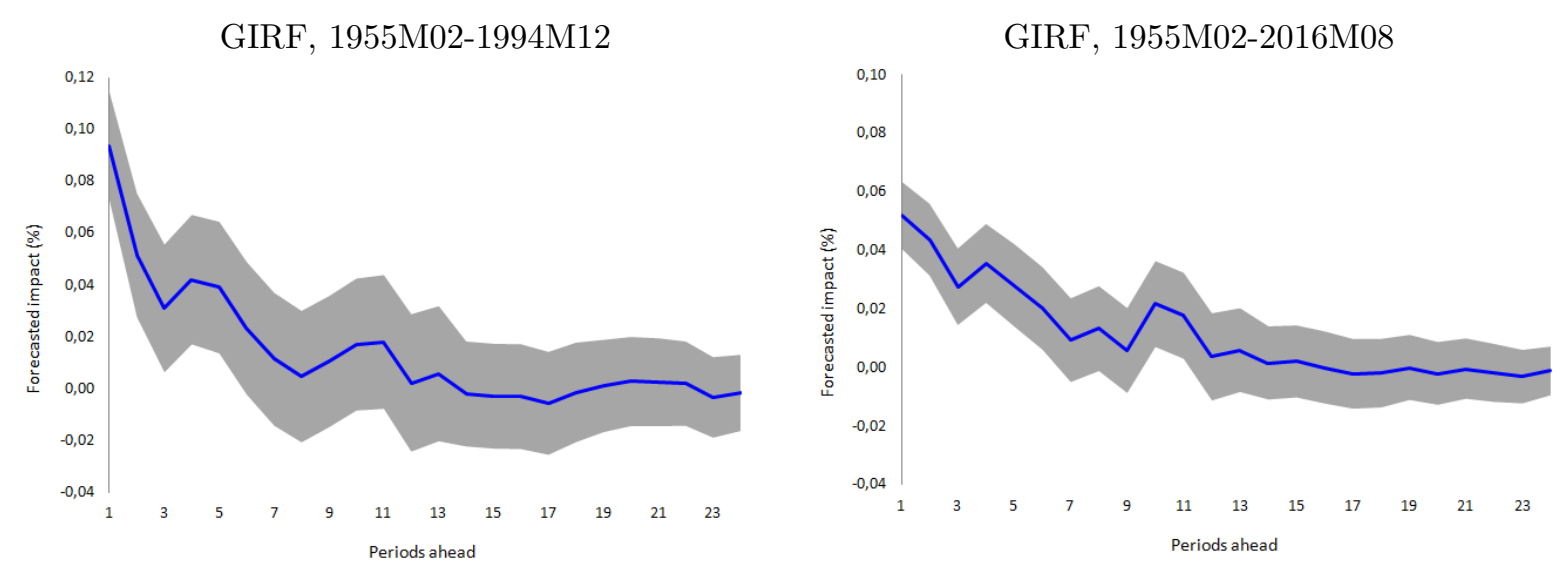

Local IRF, 1955M02-1994M12
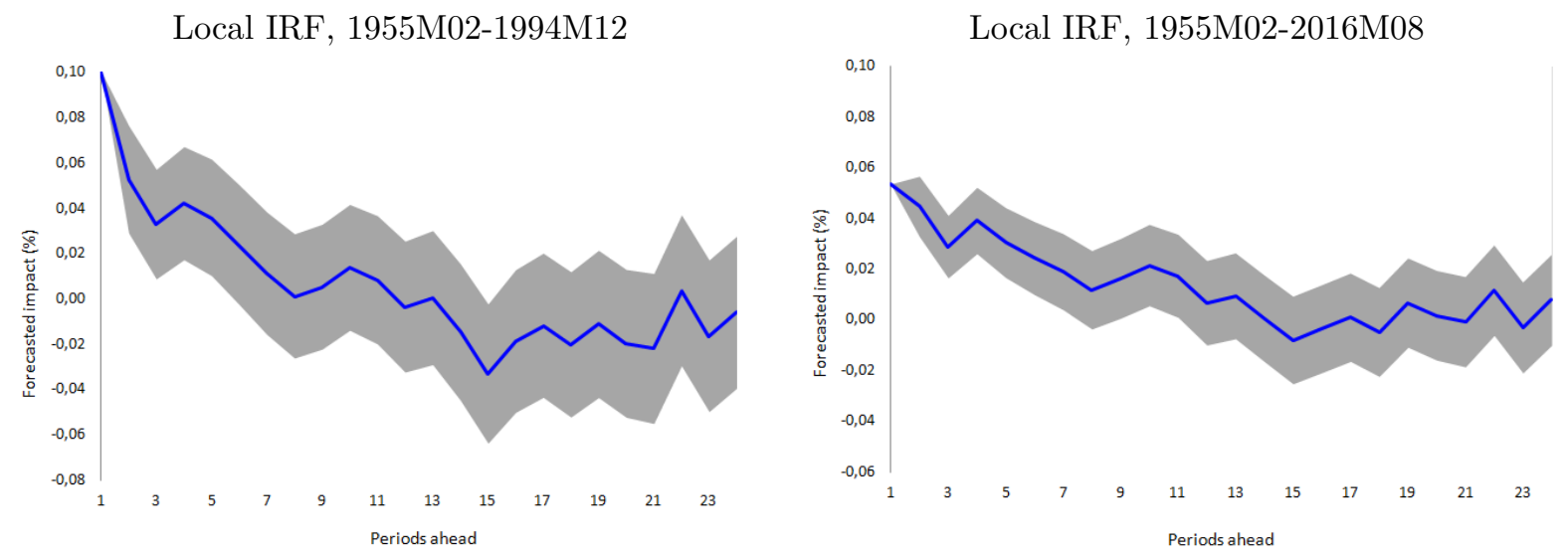

Short-run SVAR IRF, 1955M02-1994M12

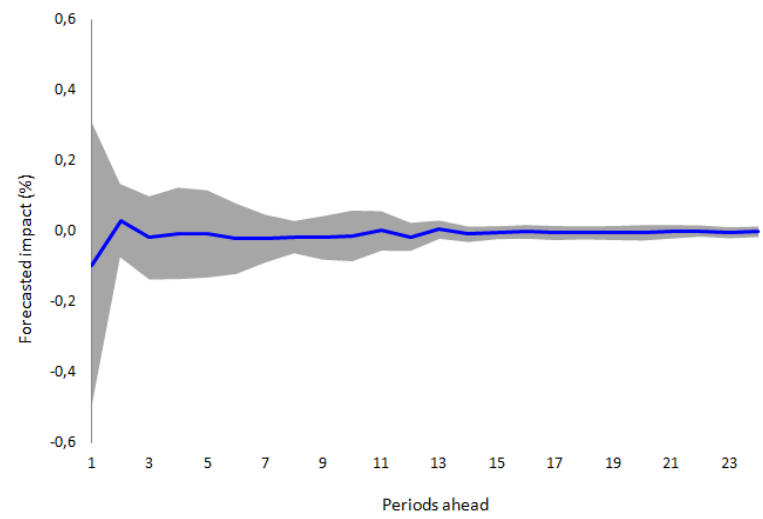

Short-run SVAR IRF, 1955M02-2016M08

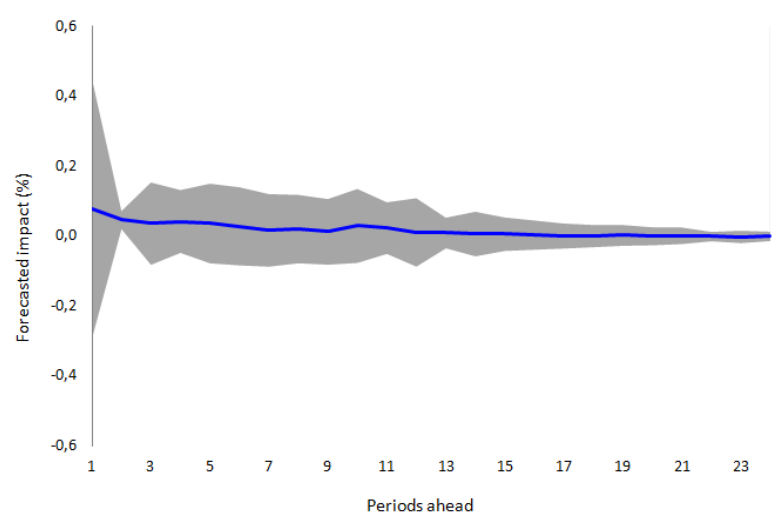


Figure 3: The response of total unemployment to reallocation shocks, exchange rate / commodity prices augmented VAR
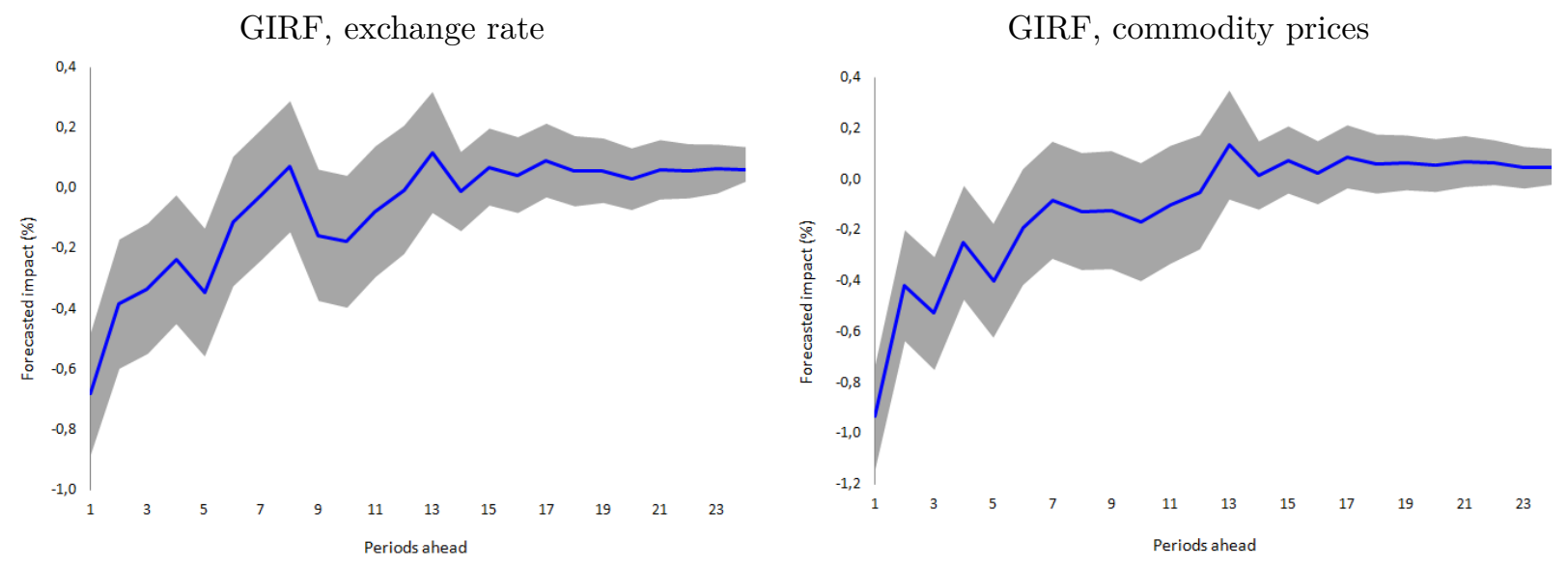

Local IRF, exchange rate
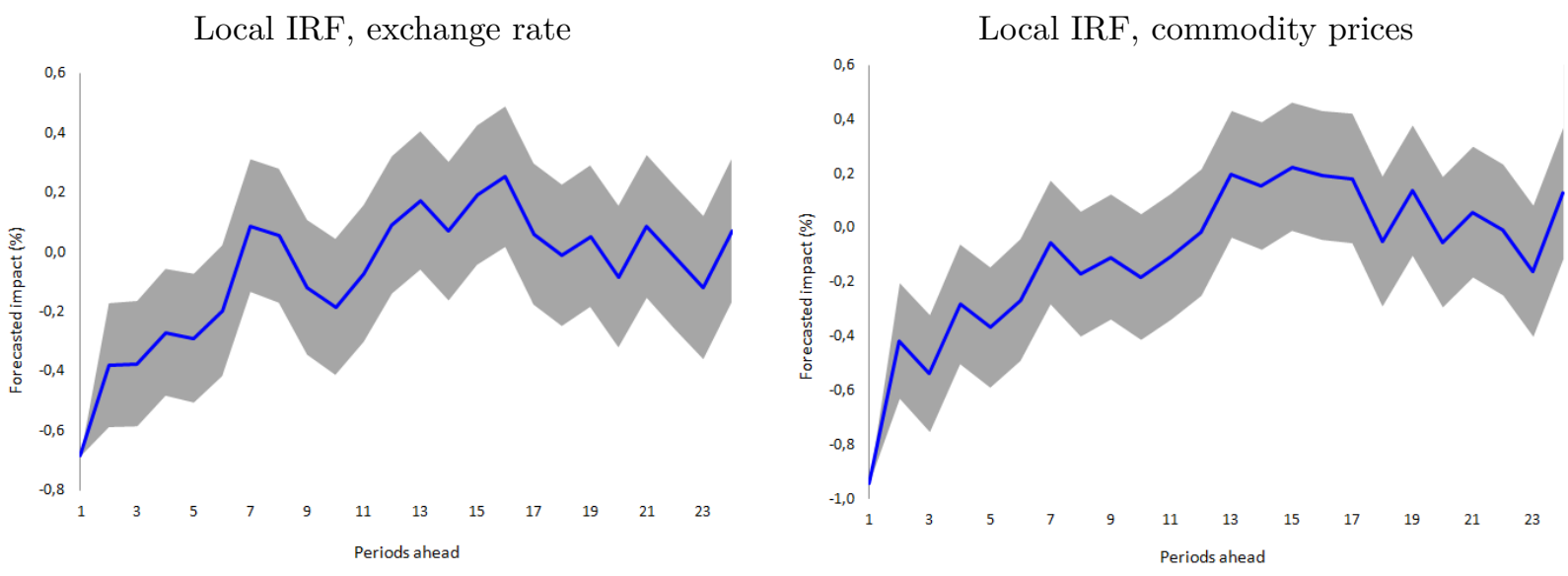

Short-run SVAR IRF, exchange rate

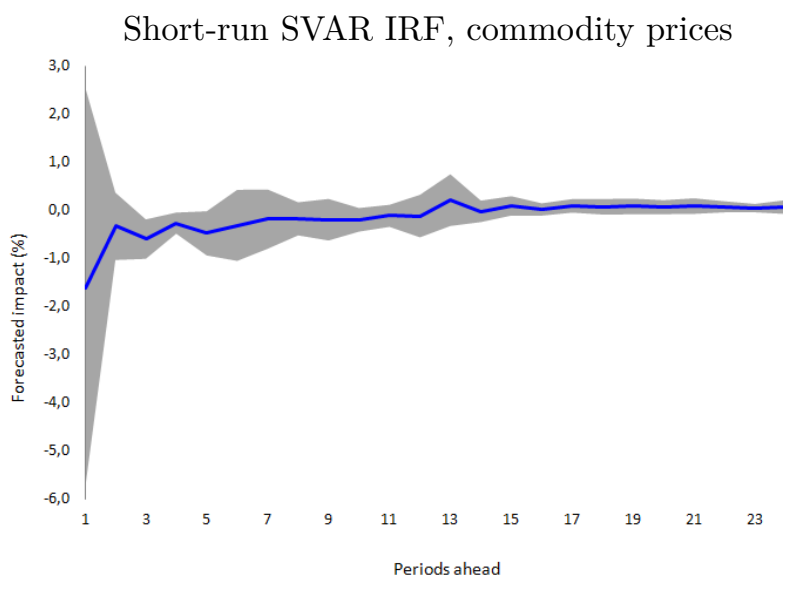


Figure 4: The response of total employment to reallocation shocks, asymmetric impulses specification
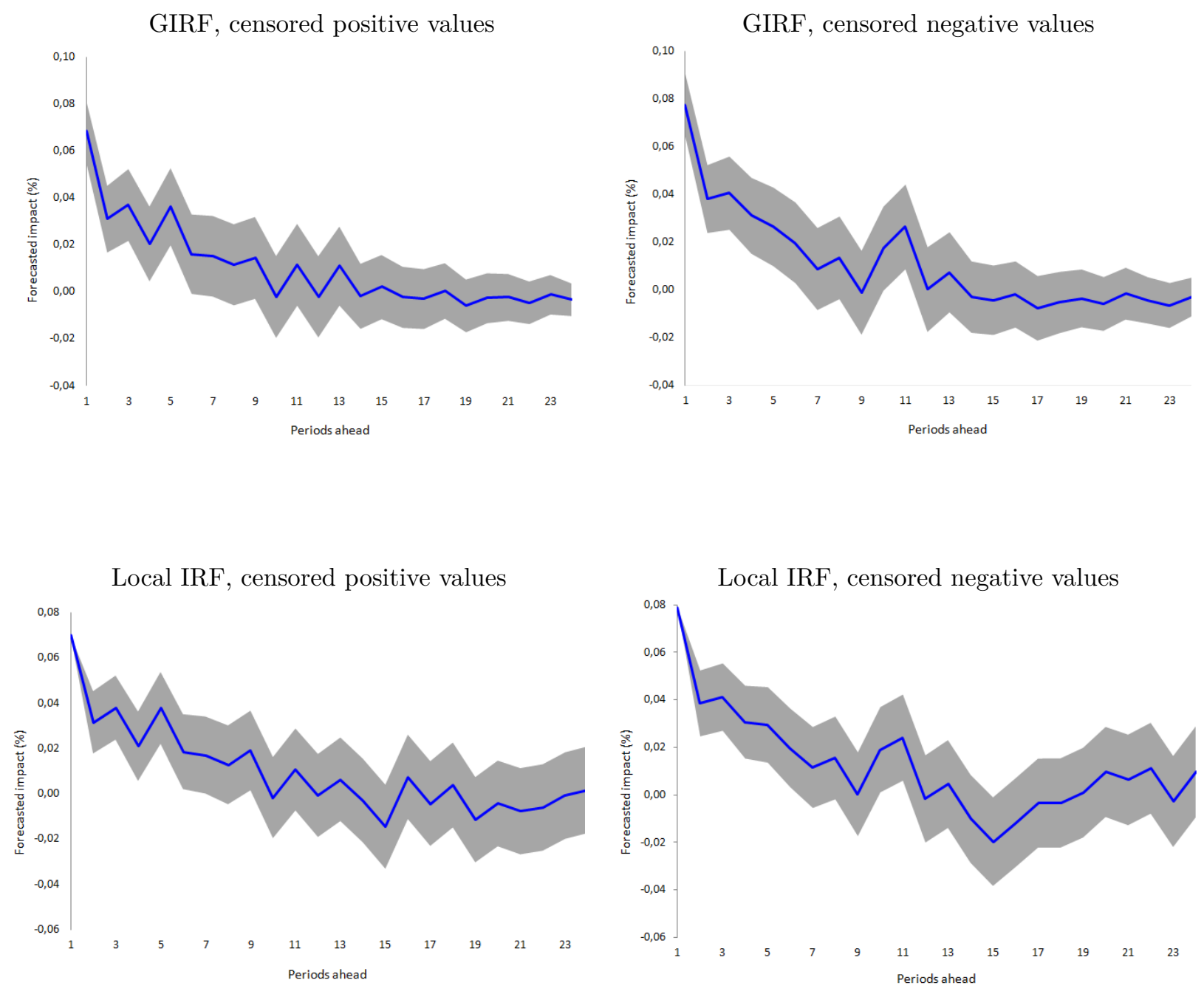


\section{Appendix}

\section{Short-run restrictions}

We impose short-run restrictions by following Sims's (1980) recursive identification scheme, so that the structural shocks $u_{i t}$ are just identified and recovered from the reduced $\varepsilon_{i t}$. As in the $\mathrm{AB}$ model of Amisano and Giannini (1997) we have:

$$
\left[\begin{array}{cc}
1 & \alpha_{12} \\
\alpha_{21} & 1
\end{array}\right]\left[\begin{array}{l}
\varepsilon_{1 \tau} \\
\varepsilon_{2 \tau}
\end{array}\right]=\left[\begin{array}{cc}
b_{11} & 1 \\
1 & b_{22}
\end{array}\right]\left[\begin{array}{l}
u_{1 t} \\
u_{2 t}
\end{array}\right] \Longrightarrow \begin{gathered}
\varepsilon_{1 t}=b_{11} u_{1 t} \\
\varepsilon_{2 t}=-a_{21} u_{1 t}+b_{22} u_{2 t}
\end{gathered}
$$

Under this scheme, sectoral shocks have no effects on aggregate employment in the current period.

\section{Long-run restrictions}

In line with Blanchard and Quah (1989), we impose long-run restrictions via the accumulated responses to structural innovations. Thus $C=\Psi_{\infty} A^{-1} B$, is the long-run response matrix, $\Psi=\left(I-A_{1}-A_{2}-\ldots . A_{\rho}\right)^{-1}$ are the estimated accumulated responses from reduced-form shocks, $A_{\rho}$ is the coefficient matrix for the lagged values of the endogenous and $B$ is the matrix of the simultaneous coefficients. Imposing $C_{2,1}=0$ implies that total employment shocks have no long-run impact on the manufacturing sector.

\section{Augmented SVAR}

Consistently with CK, we expand the bivariate VAR with the inclusion of the log-difference of the price of crude petroleum $(D Z)$. DZ would behave as a univariate autoregression and would not affect $D N$ directly. These restrictions would identify the system (Hamilton, 1994, p 330-331). We depart from CK by augmenting the underlying bivariate VAR with a third equation describing the dynamic behavior of a commodity price index instead of oil prices.

\section{Alternative Impulse Response Functions}

We employ alternative impulse response functions (IRFs) that were not available at the time of the CK publication. These are derived by the coefficient matrices of the moving average representation of a VAR (IRF to orthogonalized shocks). We look at the generalized impulse responses (GIRF) of Pesaran and Shin (1998):

$$
G I_{\chi}\left(n, \delta, \Omega_{t-1}\right)=E\left(\chi_{t+n} \mid \varepsilon_{t}=\delta, \Omega_{t-1}\right)-E\left(\chi_{t+n} \mid \Omega_{t-1}\right)
$$

where $\chi$ is the vector of endogenous, $\Omega_{t-1}$ is the information set, $\delta$ is the shock size and $n$ is the horizon.

Furthermore, following Jorda $(2005,2009)$ we use local projections instead of extrapolations. This approach is more robust to misspecification and can accommodate nonlinear and flexible specifications. The forecasts of this dynamic analysis are estimated at each period of interest rather than using the same set of information for 
longer horizons. The impulse responses from the local projections can be written as:

$$
\operatorname{IR}\left(t, s, d_{i}\right)=B_{1}^{s} d_{i}
$$

where $d_{i}$ is the shock to the $i^{\text {th }}$ variable of the VAR, $B_{1}^{s}$ are matrices of coefficients for each lag of variable 1 and $s$ is the horizon of the forecast.

\section{Data}

The dataset is extracted from the Federal Reserve Bank of St. Louis (originally from the Bureau of Labor Statistics). These are monthly observations for the employment shares of manufacturing, services, construction, financial activities, trade and government, total employment, price of crude petroleum, real effective exchange rate, producer price index and total unemployment. All series are seasonally adjusted, and the sample ranges from 1955M02 to 2016M08 containing 739 observations. Table 1 presents the variables.

\section{Additional Figures}

Here we present the impact the real exchange rate and commodity price have directly on unemployment (through simple GIRFs and local IRFs 5 :

Figure 5: Responses of Unemployment to the indicated variables
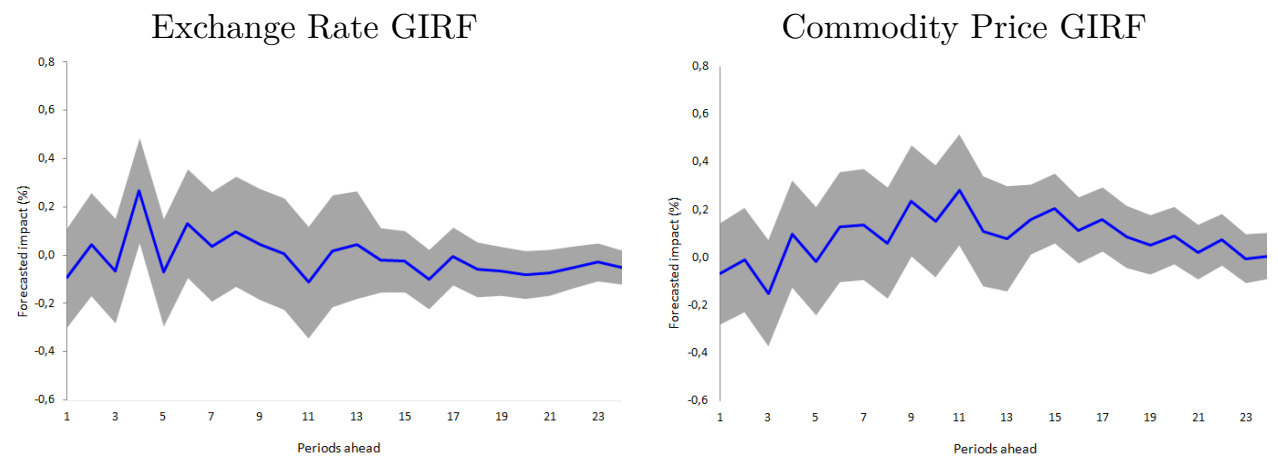

Exchange Rate local IRFs

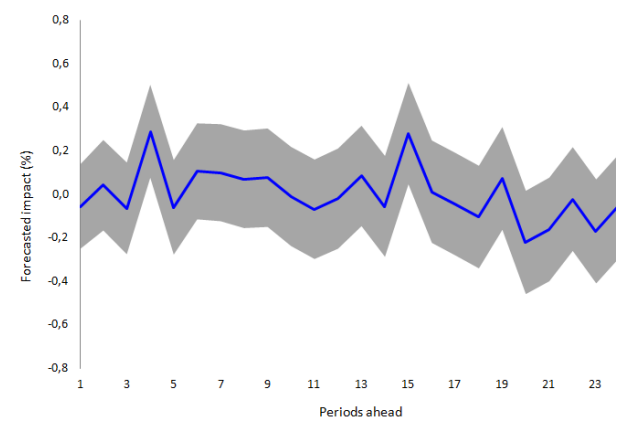

Commodity Price local IRFs

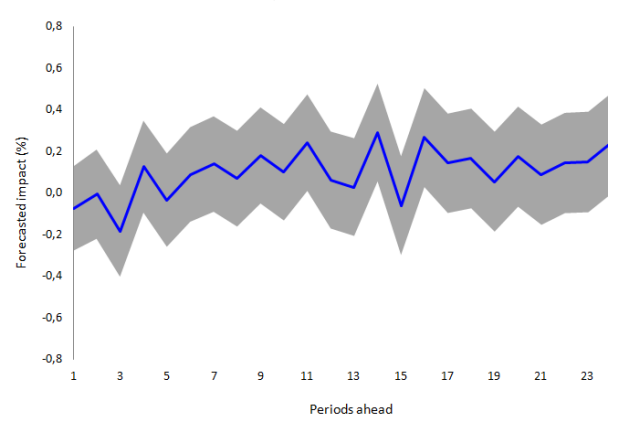

${ }^{5}$ The structural case is equivalent with the simple GIRF. 


\section{References}

Amisano, G. and Giannini C., (1997). Topics in Structural VAR Econometrics, 2nd edition.

Blanchard, O.J., and Quah D., (1989). The Dynamic Effects of Aggregate Demand and Supply Disturbances. American Economic Review, 79: 655-673.

Hamilton, J.D., (1994). Time Series Analysis.

Pesaran, H.H. and Shin Y., (1998). Generalized impulse response analysis in linear multivariate models. Economic Letters, 58: 17-29.

Sims, C., (1980). Macroeconomics and Reality. Econometrica 48, 1-48. 